\title{
Immigration Policy Reforms and Pervasive Illegal Migration: A Case of the Illegal Border Jumpers (Beitbridge Border Post).
}

\author{
Gracsious Ncube ${ }^{1}$, Nqobizitha Dube ${ }^{2}$ and Mkhokheli Sithole ${ }^{3}$ \\ ${ }^{1,2,3}$ (Institute of Development Studies/National University of Science and Technology, Zimbabwe)
}

\begin{abstract}
This paper analyses the reasons why illegal border jumping by Zimbabweans into South Africa still occurs in the light of favourable policy reforms that facilitate legal migration. Primary data was collected through questionnaires, group discussions and key informant interviews. Secondary data was also collected from relevant authorities' records and through extensive review of relevant literature. The study found and concluded that the major reasons identified for perennial illegal migration were lack of proper documentation, the limited number of visiting days given to Zimbabweans entering South Africa, travelling with undocumented minors, sudden events such as death, the lack of liquid cash and the current favourable asylum laws. The study has several recommendations among which : the urgent need to review the migration management systems of the two countries and the region as a whole and the need for measures to deal with institutionalised corruption for both countries.
\end{abstract}

Keywords: Migration, Illegal border-jumping, policy-reform, South Africa, Zimbabwe

\section{Introduction}

From the years 2008 to date, the South African government introduced immigration policy reforms that eased the legal requirements demanded when travelling to South Africa from Zimbabwe. On the other hand, there was increased efficiency in the Zimbabwean registrar general's office regarding the issuing of travel documents. However, despite these developments, illegal migration between the two countries is still rampant. Papademetriou (2005) cited in Baldwin-Edwards, $(2008,1450)$ estimates the share of unauthorized immigrants in the world's immigrant stock at between 15 and 20 percent of the total (between 30 and 40 million immigrants). Among them, the US has the largest absolute number of irregular immigrants followed by South Africa.

Southern Africa's economy and society have been shaped by human mobility and elaborate efforts to control it. The domestic and international migrant labour on which mine-based capital accumulation in Southern Africa relied for decades contributed to the structure of the region's economies, urban settlement, and primary livelihood strategies (Segatti \& Landau, 2011). Crush and Ramachandran (2010) argue that, the actual number of migrants in South Africa is unknown and unknowable. The irregular status of many migrants and the poor treatment they receive give them little interest in making their real identity known to census-takers. Zimbabwe's 2001 census data puts the number of Zimbabwean foreign-born migrants (in South Africa) at one million and two (1.02)The United Nation (2008) Migrant Stock Database provides estimates suggesting that in South Africa, the numbers of illegal migrants have been increasing since 2000 and were expected to reach 1.9 million in 2010 (or $3.7 \%$ of the population).

According to Crush and Peberdy(2005), the collapse of apartheid in South Africa brought two main changes in patterns of migration. First, there was a marked increase in temporary regular and irregular crossborder movement between South Africa and its neighbours. Migrants who wanted to work in sectors other than mining and commercial agriculture had no means of legal access to South Africa. As a result, irregular migration expanded. Secondly, South Africa became a desirable destination for economic migrants from West, East and Central Africa (Morris and Bouillion 2001).

A national attitudinal survey by the South African Migration Project (2008) found that South African antipathy to migrants affects the way in which citizens think about migration and what policy options should be pursued to curtail it. First, South Africans believe that the two main reasons why migrants come to the country are to look for work and to commit crime. Secondly, the deportation of all migrants was highly supported with special emphasis on those who were HIV positive. Third, the study results indicated that a majority of south Africans want it to be compulsory for non-citizens to carry personal identification with them at all times. Finally, South Africans feel that migrants and refugees should not enjoy the same basic rights as citizens. According to Polzer (2008), the number of Zimbabweans in the country is estimated by politicians, officials and the media to be two to three million, a figure disputed by Makina (2010), who estimates that the Zimbabwean migrant stock of South Africa only reached 763000 in 2007. 
This paper analyses the state of illegal immigration between Zimbabwe and South Africa with the intention to understand why illegal border jumping to South Africa by Zimbabweans is still persistent. The specific questions that the study seeks to answer were;

i. What is the nature of illegal migration at Beitbridge border post?

ii. What are the major reasons for illegal migration from Zimbabwe to South Africa?

iii. Has the magnitude of illegal migration risen or fallen after the bilateral institutional reforms in South Africa and Zimbabwe?

iv. What recommendations may be made to further manage illegal migration between the two countries?

\section{Methods}

The study was conducted in the city of Bulawayo, the Beitbridge border post and the mainland South African cities of Johannesburg and Durban. It made use of several sampling methods due to the differences of the type of respondents involved. Random sampling was used to select respondents who had been apprehended for attempting to cross into South Africa illegally and for individuals who had managed to enter South Africa illegally and were housed at the central Methodist church in Johannesburg and the refugee centre in Durban. Purposive sampling was used to identify key informants on both the Zimbabwean and South African side of the Beitbridge border post and the city Johannesburg due to the delicacy of the information sought. These comprised of the Police, Departments of Immigration officials, International Organisation for Migration (IOM) and the Bishop of the Methodist Church in Johannesburg. To select participants from the Cross-border transporters (Omalayitsha), snowball sampling was used as a degree of trust had to be established using referral techniques before the information could be obtained. A combination of focus group discussions, questionnaire surveys, interviews and key informant interviews were used to gather primary data. Further to that, document analysis and policy review was used to gather secondary data.

\section{Migration in Southern Africa}

The relationship between migration and development has become a central item on the global development agenda (Crush and Frayne 2007; Gundel 2002; Nyberg-Sørensen et al. 2002; Van Hear \& Nyberg Sørensen 2003; Haque 2004; Sriskandarajah 2005). Although migration and development were recognised as issues of growing international policy significance as long ago as the 1994 Cairo Conference (UN, 2004 cited in Crush and Frayne, (2007:1), little concrete progress was made thereafter in formulating a coherent response (Castles 2000). Most development policy has continued to be formulated and implemented as if the mobility of people is of little consequence (Crush and Frayne 2007). Similarly, national migration and immigration policies continued to be implemented with scant regard of its development implications. Newland (2004) points out that migration continued to be seen as an issue that lay firmly within the prerogatives of the sovereign state and states were therefore reluctant to be bound by international agreements pertaining to migration.

In 2012, the former South African Minister of finance Trevor Manuel noted that there was a need for Southern African Development Committee (SADC) member states to continue working among themselves to strengthen their economies through closer integration, burden-sharing, expanding intra-African trade and investment, and investing in infrastructure development ${ }^{1}$ (NewsDay Nov, 2012). There is growing recognition amongst SADC member states that a community of states with common interests needs to facilitate the movement of people, not just trade and investment, in order to further the process of economic integration and balanced regional development. As early as 1995, the SADC Secretariat moved to implement, a Protocol on the Freedom of Movement of Persons, however opposition to the Protocol within South Africa, Botswana and Namibia was particularly strong and effectively killed off any chance of ratification by 2000 (Oucho and Crush 2002).

Illegal migration is migration that occurs outside of the legal and institutional frameworks established by states (Baldwin-Edwards 2008, 1449). Papademetriou 2005 cited in Baldwin-Edwards (2008, 1450) identifies four common forms of illegal migration namely, unauthorised entry, fraudulent entry, visa overstaying, and violation of the terms and conditions of a visa. In the case of southern Africa, other forms of illegal migration have also been observed and these include rejected asylum seekers who are required to leave, but instead 'disappear, which has been a major problem even within the Zimbabwean immigrant community in the United Kingdom; formerly legal residents who are unable to renew their permits and this has been the case with students who have completed their studies; as well as individuals who are in technical violation of conditions of their visas or permits through such as change of employment into jobs or fields that they have not been authorised to do by the state.

In South Africa studies by the International Federation for Human Rights (2007) have pointed out that migrants, regardless of documentation live in permanent insecurity. Police control and harassment were cited as a common experience among foreign migrants. The report also revealed that ID (identity card) control accompanied by bribes; abuse and extortion of money or goods and inflicting verbal or physical abuse were 
common. Migrants are also noted to run the risk of being arbitrarily arrested and detained, facing hasty deportation without adequate verification of their legal status in South Africa.

\section{The Nature of Illegal Migration between South Africa and Zimbabwe}

Sagrera (2010) argues that international cooperation in the field of migration is scarce. Whereas the phenomenon of migration is inherently transnational, states are generally reluctant to transfer sovereignty at the supranational level and even to cooperate closely among each other to address the challenges (which often give rise to illegal migration) linked to migration (569.

The working definition of undocumented migrants given by the South African government includes any person living and working in South Africa who does not have a proper legal status (IFHR2007, 1) ${ }^{2}$. According to this definition therefore, undocumented migrants range from waged workers, circular and seasonal workers, migrants who are self employed, refugees, asylum seekers and the children of those migrants.

Polzer $(2010,2)$ argues that Zimbabwean migration is testing South Africa's legal and institutional infrastructure for migration management and refugee protection. As democratic South Africa's first large-scale in-migration from a neighbouring country, there is no institutional experience to draw upon in developing and implementing responses.

Illegal emmigration from Zimbabwe to South Africa has been associated with the abuse of human rights during and after the process. A study done by the South African Migration Project (SAMP 2006) showed that the venture of illegally migrating to South Africa from Zimbabwe was riddled with many hurdles that included arrest, armed robbers and rapists on both the Zimbabwean and South African sides. The study also revealed that one could lose his/her life if confronted by armed robbers, , the raging waters of the Limpopo or wildlife.

Save the Children UK (2005) notes that approximately $15 \%$ of individuals deported back to Zimbabwe for illegal crossing at Beitbridge border post are children. This situation has become critical for women and children who are most susceptible to abuse and exploitation that may come in the form of labour exploitation, lack of protection due to inadequate documentation, limited access to schools and other social welfare institutions, coercion of girls into the sex industry as the only means of economic survival, discrimination, and harassment by the authorities on both sides of the border (SCUK 2008).

To facilitate documentation and legal migration, the Zimbabwean government in 2010 reduced ordinary Zimbabwean passport prices from US $\$ 670$ to US\$50 per applicant. The government also recorded improved efficiency in the time required to produce a passport and also introduced online applications to aid the application process in 2012.

\section{South African Migration Controls}

Segatti \& Landau (2011) argue that although exploitative migration practices have been central to the region for more than a century, the African National Congress (ANC) did not place immigration policy high on its reform agenda. From the initial Reconstruction and Development Programme (RDP) through the neoliberal turn initiated with the adoption of the Growth, Employment and Redistribution Programme (GEAR) in 1996 to the Accelerated and Shared Growth Initiative (ASGISA) launched in 2006, the government failed to place migration among key issues for reform or to consider it a primary tool in the country's development strategy. Adoption of the SADC Treaty in 1992 implied, among other things, a commitment to lifting obstacles to circulation of the factors of production including labour. However in the case of labour commitment in the region is still arguably lacking (Oucho and Crush 2001).

Despite the provisions by both international (UN Convention on the rights of all migrant workers and members of their families) and South African law (1998 Refugees Act and 2002 Immigration Act) for a wide protection of the rights of migrants, undocumented migrants these individuals are amongst the most exposed to human rights violations and have the least legal protection and support to defend their rights (IFHR, 2007). The lack of an adequate migration policy has undermined efforts to ensure refugee protection

Until 2009 Zimbabwe was South Africa's only neighbouring country with which there was no free visa agreement, after this was introduced for Mozambique in 2005. Zimbabweans wishing to apply for a visa to South Africa had to apply at the High Commission in Harare, have an invitation letter from South Africa and prove possession of a minimum of two thousand South African rands (ZAR2000.00). A combination of this visa policy and Zimbabwean conditions (difficulty in accessing passports and hard currency) made it virtually impossible for poor Zimbabweans, especially those living in the southern parts of the country, to enter South Africa with legal visitors' documentation. This made the dominant means of entry into South Africa informal border crossing that increased vulnerability of undocumented Zimbabweans en route and in South Africa.

The South African migration policy remains geared towards security concerns and population control, based on the premise that considerable numbers of economic migrants want to come and stay in the country and that large numbers of them are "illegal" migrants. According to IFHR (2007), such a vision does not take into account the 
fact that a large majority of migrants enter South Africa legally and that a number of them are cross-border traders, seasonal, circular or temporary migrants.

Until June 2008, the United Nations High Commissioner for Refugees (UNHCR) took a conservative position regarding Zimbabweans, maintaining that the vast majority were not refugees and that the situation in Zimbabwe did not warrant a group application of the refugee definition set out in the Organisation of African Unity's (OAU) Convention Governing the Specific Aspects of Refugee Problems in Africa. An exception was the August 2007 visit to South Africa by the High Commissioner for Refugees Antonio Guterres who openly advocated for a temporary permit solution for Zimbabweans in his meetings with President Mbeki and other government officials (Polzer, and Segatti 2011). In September 2010 South Africa and Zimbabwe signed an agreement which legalized undocumented Zimbabwean migrants in South Africa before their pending deportation. According to Crush, et al (2008) this illustrates the preference for flexible, nonbinding arrangements favoured by SADC member states compared to free movement in crisis situations.

The use of the asylum system as a response to Zimbabwean immigration is a crucial element of any composite response, since it fulfils South Africa's international and domestic legal obligations to provide protection for individuals and groups who have experienced political persecution. However, according to Polzer, Kiwanuka, and Takabvirwa, the current implementation of the asylum system poses several problems. First, only a limited proportion of Zimbabweans has experienced individual political persecution and therefore qualifies for the current, narrowly interpreted conditions for asylum. Second, for several years, including before the large-scale arrival of Zimbabweans, the asylum system has been experiencing institutional difficulties so that many asylum seekers cannot gain physical access to Refugee Reception Offices (RROs) or have to wait long periods for their papers to be processed. Of the 44000 Zimbabwean asylum applications that had been filed at the end of 2007, only about 1000 had been granted, whereas about 9000 had been rejected leaving 34000 pending applications (2010).

While some skilled Zimbabweans continue to apply for and receive normal work and study permits, as was the case before the escalation of the Zimbabwean crisis, the Immigration Act provides limited opportunities for persons from neighbouring countries to migrate legally. There are, for example, no traders' permits, job seekers' permits or permits for unskilled workers that are not attached to an employer. The general structural impact of this gap, which also reflects on Zimbabweans, is an increase in undocumented migration and increased pressure on the asylum system, which is used as an alternative means of accessing permission to remain in the country and work.

Other government departmental policies have however been instituted to aid the management of migration between South Africa and Zimbabwe. These include South Africa's Department of Education's introduction of an initiative to facilitate the employment of qualified Zimbabwean teachers mostly in the field of sciences. Furthermore, South Africa's Department of Health recently instituted a directive that antiretroviral treatment (ART) for HIV and AIDS should be made available to refugees and asylum seekers irrespective of whether they hold documents. However, the Department has made no effort to provide employment opportunities to qualified Zimbabwean medical personnel who are already in the country, in spite of a dire shortage of South African skills in this area.

\section{Determinants of Illegal Migration}

In analysing the push and pull factors of migration between South Africa and Zimbabwe Dube, Nkala and Sithole (2012) found that the factors driving migration from Zimbabwe to South Africa include on one hand push factors such as unemployment, the deteriorating economy, political persecution and uncertainty, pursuit of family reunion, the migration band wagon and historical ties. On the other hand, migration to South Africa is also driven by the illusion of better employment opportunities in that country, commodification of South African products in Zimbabwe and influence of both the South African and international media that portray Zimbabwe as a pariah state.

To ascertain the determinants and reasons for illegal migration despite the policy reforms a qualitative study was carried out in August 2011. The main hypothesis of the study was that Zimbabweans have continued to enter South Africa illegally for various reasons despite policy reforms that promote legal travel. According to Polzer (2010), estimates on the number of Zimbabweans in South Africa in early 2008, based on a range of data sources, is around one million. However, accurately establishing the number of Zimbabweans in South Africa, as with all largely undocumented migration flows, is virtually impossible, since even a large-scale survey such as the census regularly fails to capture many of the country's migrants. Furthermore, numbers may change quite suddenly, for example as many Zimbabweans returned home to vote in March 2008. 


\section{Results \\ 3.1 The Nature of Illegal Migration at Beitbridge Border Post}

Interviews with respondent groups revealed that there are four major forms of migration which are firstly, crossing through the bush between the two countries far from the designated border crossing point. However, this form of crossing is considered possible only when the river has shallow patches in the dry season. It is mostly facilitated by ground transporters who are locally known as impisi in the local language meaning hyena. From the group discussions with the ground transporters, average charges for this form of crossing cost four hundred South African Rands (ZAR400) per head, for a one way trip. Group discussions also revealed that the majority of individuals taking part in this form of illegal migration were deportees, referred individuals and individuals seeking employment on nearby farms most of them ground transporters in their own right. This form of crossing is considered the most dangerous as it is plagued by criminal activities that occur in the bush.

Secondly, crossing under the border bridge was also cited during the group discussions with the ground transporters. This type of illegal crossing was said to be rare and dependent on the security personnel manning the bridge. However, the costs associated with this form of crossing are said to vary, making actual estimates very inaccurate.

Thirdly, crossing at the designated points illegally was cited by all interviewed vehicle transporters as the most common form of illegal migration. This is done through a complex web relationship cited by the vehicle transporters. This relationship exists amongst the various authorities and actors in illegal migration at the border post. The average cost for this form of crossing is estimated at one thousand - two hundred South African Rands (ZAR1200). It does not have any distinct participant as it draws from numerous social groups including children. The practice is highest during the festive Christmas season.

Fourthly, an interview with a key informant from the immigration department revealed that there is an increase in the illegal crossing of infants who may not have adequate documentation These included small babies and children who cross with their parents and/or guardians without passports or even affidavits required from those who are not the registered parents of the travelling minor.

\subsection{Reasons for Illegal Migration}

Various reasons were cited by different groups of respondents. Focus group discussions with the ground transporters revealed that the majority of illegal migrants did not have the proper documentation, that is, passports or Emergence Travellers Documents (ETDs) that are required to enter South Africa legally. The major reason for the lack of documentation cited was that the passport application fees were still prohibitive given that the majority of their clients were in the very low income bracket.

They further stated that some individuals had passports but do not use them because of the limited number of days given to them by the South African Immigration authorities at the border. The limited days (maximum 90/annum) are in direct conflict with the need to find gainful employment in South Africa which may take months, hence gaining entry through the bush (illegally) becomes an attractive option.

Furthermore, some individuals risk arrest if they use the designated channel as they are wanted for various crimes either in South Africa or Zimbabwe however the need and desire to visit makes the bush crossing option highly attractive to them.

Results from key informants working with the Zimbabwean Immigration department revealed that some illegal migrants hold valid passports but problems resulting from violation of migration agreements such as overstaying in South Africa force them to opt for illegal crossing. This is because once one overstays they are charged a maximum fee of three thousand South African Rands (ZAR3000) while illegal crossing costs between five hundred South African Rands (ZAR500) and eight hundred South African Rands (ZAR800) depending on the time of the year. The rainy season is usually the most expensive due to the increased challenges of having to cross the overflowing Limpompo River.

Another issue cited was that some of the boarder jumpers will be travelling with undocumented minors. Failure to acquire proper travel document for the minors due to the absence of one parent or birth certificates necessitated illegal crossing for the sake of the children. On the other hand, the South African officials also under certain circumstances refuse to allow Zimbabweans to enter South Africa (those using suspicious or fake travel documents).

Furthermore, the distance from the border for individuals who live close to the border fence but far from the designated entry point was cited as another reason for illegal entry. Further interactions with the respondents revealed that the issue of time constraints was also a major reason for illegal migration. They highlighted that even if individuals wanted proper travel documents, the waiting period (approximately seven weeks) was longer than the off-days one may have been afforded by the employer back in South Africa. As such, emigrants return to Zimbabwe to apply for passports and once the application process is complete, they return to work in South Africa through illegal means while they wait for the passport to be processed. 
Another point of note is that most of the Zimbabweans based in South Africa still maintain ties with the families back at home. Due to sudden eventualities such as death of family members, these individuals who are already living in South Africa illegally, will have to travel back home and will have no choice but to cross illegally.

\subsection{Successful and Unsuccessful Illegal Migrants}

Respondents who had attempted illegal migration also highlighted most of the reasons already stated above however they added that the South African asylum laws currently in place favoured the practice of illegal immigration in a pseudo fashion. This was because if an individual was granted asylum they automatically were legible for employment and such social necessities as opening a bank account. However with a passport one still needed to get a work permit to access these necessities. With asylum no visit days were imposed on the immigrant hence one could be in South Africa for longer periods of time than with a passport making it easy to work, survive and remit money to Zimbabwe. It therefore made economic and logistical sense to most of the immigrants with asylum (72\%) to use the asylum in South Africa and cross illegally when they needed to go back home to Zimbabwe.

\subsection{Effects of Policy Reforms on Illegal Migration}

Both ground and vehicle transporters indicated that ever since the policy reforms were put to effect, their business experienced a major downturn. When prompted for estimates, ground transporters indicated that they had lost approximately $50 \%$ of their business while vehicle transporters indicated that the losses varied with respect to seasons, with the festive season remaining almost unchanged but the rest of the year was having significant business losses above $50 \%$. Key informants from the security agents and the IOM also indicated that the numbers of illegal migrants had reduced but the actual reduction in figures were difficult to estimate due to factors such as seasons and daily repeat deportees. Interviews with a key informant at the central Methodist church in Johannesburg also indicated that the numbers of new entrants to the church had decreased though sporadic waves of individuals arriving from Zimbabwe were still not out of the ordinary.

\subsection{Major Players in Illegal Migration at Beitbridge Border Post}

The most active participants in illegal migration are the ground transporters who are mostly Beitbridge locals and are involved in the transportation of mostly low income clients. These link up with the to-be border jumpers and lead them through known trails and stops. Local villages and homes have become check points and they facilitate the process through aiding and abating

The small vehicle and bus transporters also take an active role in the activities through their links with would be migrant and migrants already in South Africa who request the illegal transportation of selected individuals. Respondents indicated that the authorities at the border post also facilitate a significant part of the illegal migration process through cooperating with transporters and accepting bribes thus, making them major players in the act as well.

Both sets of transporters (ground and vehicle) indicated an uneasy relationship between the two parties with one blaming the other for not understanding the trade well enough. However, when asked what they would do if illegal migration was contained and came to an end, the ground transporters indicated that this would be a highly undesirable state of affairs as this was their main source of livelihood. They indicated that the reforms were negatively affecting their business already and any further reforms would relegate them to dire poverty. The vehicle transporters echoed similar sentiments indicating that they had already built their lives around this livelihood strategy as some had acquired vehicles on loan to boost their trafficking business, thus halting illegal migration would lead to the repossession of their assets and spell despair for their families in Zimbabwe that they support using remittances from illegal migration activities.

\subsection{Conclusions}

\section{Conclusions and Recommendations}

The study found that illegal migration remained pervasive even after the policy reforms although there has been a notable reduction in the numberst. Several reasons were cited to this end, which included the lack of proper documentation, the limited number of visiting days given to Zimbabweans as they enter south Africa, cases of individuals wanted for various crimes, situations where individuals have violated their migration conditions through overstaying, cases of travelling with undocumented minors, the possession of suspicious or unknown travel documents, distance to the border crossing point, time constraints associated with obtaining travel documents, sudden events such as death, the lack of liquid cash and the current favourable asylum laws. Moreover, ground and vehicle transporters indicated that ever since the reforms, business has been on a downturn. This saw them losing approximately 50\% of their business while vehicle transporters' losses varied with respect to seasons, with the festive season being the peak. Key informants from the security agents and the IOM also indicated that the numbers had reduced. 
The major forms of illegal migration were crossing through the bush between the two countries, crossing under the bridge linking the two countries, crossing at the designated points illegally and subtle illegal crossing with undocumented infants. The most active participants in illegal migration are the ground transporters, the small vehicle and bus transporters and the authorities at the border post.

\subsection{Recommendations}

There should be improved access to vital documents such as birth certificates which will allow individuals to access travel documents. This will also help in revising those aspects of law that prohibit access to such documentation, which include, among others, citizenship and the presence of parents in the case of children, absence of which may result in children failing to get birth certificates.

Moreover, resumption of the border passes that used to be issued by Zimbabwean immigration would promote documented migration and curb daily illegal crossing to work in South African farms. These passes were legally recognised crossing documents issued to Zimbabwean locals resident in Beitbridge town and the villages near the border post who had a common culture with the people on the immediate South African side. These were mainly the Venda speaking people of Zimbabwe.

There is also an urgent need to review the migration management systems of the two countries and the region as a whole. This will have to address the major objectives either in favour of closed borders or the free movement of labour as advocated for in the 1992 SADC treaty. It will further allow for the review of asylum and travel documentation laws and extinguish the current scenario that seems to reflect laws or official conditions that encourage illegal migration.

There is also an urgent need to study what the effect of policy reforms is on to the livelihoods of transporters and the possible alternatives that may exists for them. This will provide safety nets and avoid problems that may arise from poverty and unemployment of this group of individuals. Finally, awareness campaigns to educate people on the dangers of illegal migration should continue to be held so that they may expose the horrors of illegal migration and encourage individuals to make use of designated entry points. Furthermore, there is need for measures to be put in place to deal with institutionalised corruption for both countries.

\section{Acknowledgements}

First and foremost we would like to thank Professor Smile Dube, (who was a visiting Professor at IDSNUST during the inception of this paper), for all the expert counsel he gave us towards the success of this study. We wish to express our sincere gratitude to him for his constructive criticism and encouragement throughout the course of this study. To the Executive Dean of the Faculty of Commerce at the National University of Science and Technology, thank you for the financial support you gave towards the successful completion of this study. We also express gratitude to our fellow colleagues at IDS-NUST for the support given through proof-reading and critiquing our work. From Beitbridge border Post, we feel indebted to the Zimbabwe Republic Police personnel, members from the President's Office, Omalayitsha, the IOM officials, Departments of Immigration Officials and all the migrants interviewed therein for their cooperation during our fieldwork. In Johannesburg, our sincere gratitude goes to the Bishop of the Methodist Church. If it was not for their cooperation, this study would not have been a success. Above all we give thanks to God the Almighty for guiding us throughout the course of this study.

\section{References}

[1]. Baldwin-Edwards, M. (2008). "Towards a Theory of Illegal Migration: Historical and Structural Components." Third World Quarterly 29 (7): 1449-1459.

[2]. Castles, Stephen. (2000). "International Migration at the Beginning of the Twenty-first Century." International Social Science Journal 52 (3): 269-81.

[3]. Consortium for Refugees and Migrants in South Africa. (2008). Protecting Refugee Asylum Seekers, and Immigrants in South Africa. CRMSA: South Africa.

[4]. Crush, Jonathan, and Sujata Ramachandran. (2010). "Xenophobia, International Migration and Development." Journal of Human Development and Capabilities: A Multi-Disciplinary Journal for People-Centered Development 11 (2): 209-228.

[5]. Crush, Jonathan, \& Bruce Frayne. (2007). 'The Migration and Development Nexus in Southern Africa: Introduction.” Development Southern Africa 24 (1): 1-23.

[6]. Crush, Jonathan. eds. (2008). "The Perfect Storm: The Reality of Xenophobia in Contemporary South Africa". SAMP Migration Policy Series 50, Southern African Migration Programme, Queen's University, Kingston, Canada, and Institute for Democracy in South Africa, Cape Town, South Africa.

[7]. Crush, Jonathan, Vincent, Williams, and Sally, Peberdy. (2005). "Migration in Southern Africa." Paper prepared for the Policy and Analysis Research Programme, Global Commission on International Migration, Geneva.

[8]. Dube, Nqobizitha, Mkhokheli, Sithole and Peter, Nkala. (2012). "Assessing the Causes and Effects of Contemporary Labour Migration between Zimbabwe and South Africa." Paper presented at the Global Business and Technology Association Conference, New York, 10 - 14 July 2012. 
Immigration Policy Reforms and Pervasive Illegal Migration: A Case of the Illegal Border...

[9]. Forced Migration Studies Programme. (2010). "Population Movement in and to South Africa." FMSP Migration Fact Sheet. University of Witwatersrand, Johannesburg. Accessed on 13 March 2013. http://www.migration.org.za/report/populationmovements-and-south-africa.

[10]. Gundel, Joakim, (2002). "The Migration-Development Nexus: Somalia Case Study.” International Migration 40(5): 255-77.

[11]. Haque, Shahidul. (2004). "The Nexus between Migration, Globalization and Development: A New Discourse." In Orderly and Humane Migration: An Emerging Development Paradigm, edited by Priti Kumar Mitra and Jakir, 35 - 50. International Organisation for Migration: Geneva.

[12]. International Federation of Human Rights. (2007). "Surplus People: Undocumented and Other Vulnerable Migrants in South Africa." International Federation of Human Rights Accessed March 14. http://www.fidh.org/IMG/pdf/za486a_Exesum.pdf.

[13]. International Organisation for Migration. (2006). "Beitbridge Migration Survey: Results from the Second Survey of Deportees Receiving Humanitarian Assistance in Beitbridge, Zimbabwe.” Beitbridge: International Organisation for Migration.

[14]. Makina, Daniel. (2007). "Survey of Profile of Migrant Zimbabweans in South Africa: A Pilot Study." Pretoria: University of South Africa.

[15]. Morris, A and A, Bouillon, eds. (2001). African Immigration to South Africa: Francophone Migration of the 1990s. Protea and IFAS, Pretoria.

[16]. Newland, K. (2004). "Migration as a factor in development and poverty reduction: the impact of rich countries' immigration policies on the prospects of the poor". In Impact of Rich Countries' Policies on Poor Countries: Towards a level playing field in development cooperation, edited by Picciotto, Robert and Rachel Weaving, 187 - 214. New Brunswick, NJ: Transaction.

[17]. Sørensen, Nyberg, Nicholas, Van Hear, N and Engberg-Pedersen, Poul. (2002). "The Migration-Development Nexus: Evidence and Policy Options." International Migration 40 (5): 49-73.

[18]. Oucho, John, and Crush. Jonathan. (2001). "Contra Free Movement: South Africa and SADC Migration Protocols." Africa Today 48 (3): $139-58$.

[19]. Papademetriou, D. (2007). 'The Global Struggle with Illegal Migration'. Migration Policy Institute, Forced Migration Studies Programme and Musina Legal Advice Office 2007. Special Report: Fact or Fiction? Examining Zimbabwean Cross-Border Migration into South Africa. Forced Migration Studies Programme. University of the Witwatersrand, Johannesburg.

[20]. Polzer, Tara. (2008). "Responding to Zimbabwean Migration in South Africa: Evaluating Options." South African Journal of International Affairs 15 (1): 1-28.

[21]. Polzer, Tara and Aurelia, Segatti. (2011). "From the Defence of Migrants' Rights to New Political Subjectivities: Gauteng Migrants' Organisations after the May 2008 Crisis.” In Exorcising the Demons Within: Xenophobia, Violence, and Statecraft in Contemporary South Africa, edited by Loren B. Landau. Johannesburg: University of the Witwatersrand Press.

[22]. Polzer, Tara, Monica, Kiwanuka, and Kathryn, Takabvirwa. (2010). "Regional Responses to Zimbabwean Migration, 2000-2010." Open Space: On the Move: Dynamics of Migration in Southern Africa 3 (3): 30-34.

[23]. Sagrera, R. H. (2010). "The EU-Russia readmission-visa facilitation nexus: an exportable migration model for Eastern Europe?". European Security 19 (4): $569-584$

[24]. Save the Children UK. (2007). 'Children Crossing Borders: Report on Unaccompanied Minors Who Have Travelled to South Africa'. Pretoria: Save the Children.

[25]. Segatti, Aurelia and Landau, Loren. B. (2011). "Contemporary Migration to South Africa". Agence Française de Développement and The International Bank for Reconstruction and Development / The World Bank. Washington USA.

[26]. Government Gazette (2002) South African Immigration Act 443 (23478). Cape Town, Republic of South Africa.

[27]. South African Migration Project. (2006). Queen's University2006. Sunday Mail, 2006-10-29. Available Online from: http://www.queensu.ca/samp. Accessed 14 December 2012

[28]. Government Gazette (1998) Refugees Act 130:1998. Cape Town, Republic Of South Africa

[29]. Southern African Migration Programme. (2000). "Losing Our Minds: Skills Migration and the South African Brain Drain". Migration Policy Series 18. Southern African Migration Programme, Queen's University, Kingston, Canada, and Institute for Democracy in South Africa, Cape Town, South Africa.

[30]. Southern African Migration Project. (2008). 'The Perfect Storm: The Realities of Xenophobia in Contemporary South Africa'. SAMP Migration Policy Series No. 50, SAMP, Cape Town.

[31]. Sriskandarajah, Dhananjayan. (2005). Migration and Development. Paper prepared for the Policy Analysis and Research Programme of the GCIM, Geneva.

[32]. United Nations. (2005). Expert Group Meeting on International Migration and Development, New York, 6-8 July.

[33]. United Nations High Commission for Refugees. (2007). 'Refugee Protection and Mixed Migration: A 10-Point Plan of Action'. Geneva: UNHCR, 2007.

[34]. Van Hear, Nicholas and Nyberg Sørensen Ninna. eds. (2003). "The Migration-Development Nexus”. International Organisation for Migration. Geneva.

\footnotetext{
${ }^{1}$ NewsDay Nov., (2012). November 25, 2012 it's up to Africa to lift up itself. Accessed on o7/12/12 from http://www.newsday.co.zw/2012/11/25/its-up-to-africa-to-lift-up-itself-manuel/.

${ }^{2}$ Surplus People: Undocumented and Other Vulnerable Migrants in South Africa http://www.fidh.org/IMG/pdf/za486a_Exesum.pdf.
} 